\title{
Lifestyle issues: \\ What do I tell my patients? \\ Smoking and diet
}

\author{
C BENONI, MD
}

\begin{abstract}
During the past decade, smoking has been recognized as a risk factor in inflammatory bowel disease (IBD). Smoking is associated with Crohn's disease, and nonsmoking with ulcerative colitis. The biological rationale behind these findings is not known. Because of the negative effects of smoking, advice to patients with IBD cannot differ from advice given to any patient. In families with IBD, young healthy members should be advised never to start smoking. In Crohn's disease, a fat-reduced diet will be necessary when bile salt metabolism is disturbed. Prospective trials with unrefined carbohydrate fibre-rich diets or low-residue diets versus normal diets show no difference in the clinical course of Crohn's disease. Thus the patient should have a well balanced diet with unrestricted fibre intake, supplemented in case of malabsorption with vitamins and minerals. Diet counselling itself has proved beneficial, probably because of optimization of nutritional status. In ulcerative colitis, patients may be lactose intolerant without lactase deficiency. Low dietary fibre intake doses does not seem to be of importance. The ulcerative colitis patient should be advised to eat a normal to high fibre diet. Recent studies have suggested a possible beneficial effect of dietary supplementation with fish oil. Can J Gastroenterol 1990; $4(7): 355-359$
\end{abstract}

Key Words: Crohn's disease, Diet, Management, Ulcerative colitis

\section{Que recommander aux patients en terme de mode de vie?}

\section{Tabagisme et régime alimentaire}

RESUME: Au cours des dix dernières années, le tabagisme a été reconnu comme facteur de risque dans les maladies inflammatoires de l'intestin (MII). La maladie de Crohn est associée aux fumeurs et la colite ulcéreuse aux non-fumeurs. Aucune explication biologique connue ne justifie ces résultats. A cause des dangers de la cigarette, les conseils à dispenser aux patients porteurs de MII devraient être les mêmes pour tous. Dans les familles souffrant de MII, on devrait recommander aux jeunes gens en bonne santé de ne jamais commencer à fumer. Dans la maladie de Crohn, un régime pauvre en matières grasses s'impose lorsque le métabolisme des sels biliaires est perturbé. Parce que le risque de carries associées à la maladie de Crohn est élevé, les patients devraient limiter leur consommation de sucre.

Department of Medicine, University Hospital of Lund, Lund, Sweden

Correspondence and reprints: Dr Cecilia Benoni, Department of Medicine, University Hospital of Lund, S-221 85 Lund, Sweden
$\mathrm{D}$ URING THE PAST DECADES, THE prevalence of smoking has decreased; this is probably one important explanation for why several authors independently noted that patients with ulcerative colitis tended to be nonsmokers or ex-smokers. Also, in men with ulcerative colitis a deficit of deaths from diseases of the circulatory and respiratory systems was reported (1). In the mid 1970s a low prevalence of smoking in ulcerative colitis patients was observed and interpreted as an effect of the disease (2). Harries et al (3) described in 1982 that only $8 \%$ of patients with ulcerative colitis were smokers but found no difference between patients with Crohn's disease and controls. It was noted that many patients with ulcerative colitis were ex-smokers who had given up smoking usually before the onset of symptoms. Bures et al (4) observed the same association but could also link Crohn's disease with smoking. Using data derived from the Boston Collaborative Drug Surveillance Program, Jick and Walker (5) confirmed a negative association between smoking and ulcerative colitis and also found an association between heavy smoking and low risk.

A claim by one of the author's male ulcerative colitis patients, that he got worse every time he stopped smoking 
Les études prospectives comparant les régimes normaux aux régimes riches en fibres et en hydrates de carbone non raffinés ou pauvres en fibres ne révèlent aucune différence dans l'évolution clinique de la maladie de Crohn. Ainsi, le patient devrait suivre un régime bien équilibré avec un apport illimité de fibres et complémenté, en cas de malabsorption, par des vitamines et des minéraux. Sans doute parce qu'elles optimisent le statut nutritionnel, les consultations diététiques s'avèrent bénéfiques. Dans la colite ulcéreuse, les patients peuvent souffrir d'une intolérance au lactose sans toutefois manifester d'insuffisance. Les régimes pauvres en fibres ne semblent pas avoir d'importance. On devrait recommander un régime normal ou riche en fibres au patient porteur de colite ulcéreuse. Des études récentes font état des avantages possibles d'un apport complémentaire d'huile de poisson.

and well when he started again, initiated a study comparing smoking habits in ulcerative colitis and Crohn's disease, thus taking into consideration that the illness itself could influence smoking habits. The interest was focused on whether stopping smoking was associated with the onset of disease. In line with the other studies, a low percentage of ulcerative colitis patients who smoked was found $(13 \%)$ compared with a high percentage of Crohn's disease patients (49\%). Randomized surveys in the general population show 30 to $32 \%$ smokers. A large proportion of male ex-smokers with ulcerative colitis was found, with disease onset generally observed one to four years after stopping smoking (Figure 1). Some patients also reported deterioration after stopping smoking temporarily. Ex-smoking was rare in Crohn's disease patients $(16 \%)(6,7)$.

In Mormons, who abstain from smoking (or drinking coffee, alcohol and cola drinks), the prevalence of ulcerative colitis has been found to be four times higher than in the general population (8). Comparing current habits in patients with ulcerative colitis and Crohn's disease, Holdstock et al (9) also found a low prevalence of smoking in ulcerative colitis.

The weakness of these first studies lies in the selection of controls and that they mainly describe current smoking habits and thus the prevalence of smoking. In a case control study of smoking and ulcerative colitis using community controls, Logan et al (10) found a relative risk of 3.8 for nonsmoking on current habits and the risk was nearly doubled (6.2) if habits at onset of the disease were examined. It was noted that the majority of male ex-smokers had stopped smoking before the onset of symptoms. In a further analysis, Logan and Langman (11), using nonsmoking as a standard, could show an increased risk for ex-smokers (2.8) and a decreased risk for smokers $(0.32)$ at onset in ulcerative colitis. Smoking habits in Crohn's disease were investigated in a case control study (12). Patients with Crohn's disease were significantly more likely to be smokers than controls, the relative risk for smokers compared with nonsmokers at onset of symptoms being 4.8 . The relative risk for smoking women was 8.2

In a risk factor study initiated by findings in their mortality study of patients with ulcerative colitis, Gyde et al (1) confirmed that patients with ulcerative colitis smoked significantly less than matched controls and thus could explain the earlier findings (13).

Several studies from different countries have confirmed the findings that nonsmoking is associated with ulcerative colitis and smoking with Crohn's disease (14). Despite differences in methods used, choice of controls and to some extent definitions of smoking, the data are remarkably consistent. In a recent meta-analysis performed by Calkins (14), data are analyzed from 10 of at least 20 studies on the topic.

Comparing current smoking and former smoking to lifetime nonsmoking, the analysis confirms earlier reports. In ulcerative colitis, the risk for smokers is less than half that for nonsmokers (pooled odds ratio 0.41). Reversed, the risk for lifetime nonsmokers is increased threefold (odds ratio 2.9). The risk for ex-smokers is $60 \%$ higher than for nonsmokers (odds ratio 1.64). In Crohn's disease, the risk for smokers is doubled compared to nonsmokers (odds ratio 2.0) and the risk for ex-smokers is $80 \%$ increased (odds ratio 1.8). This increased risk in ex-smokers can be interpreted as an ex. cess risk associated with smoking in Crohn's disease. In smoking patients with ulcerative colitis a dose-response analysis shows a significant decrease in risk with increasing use and for exsmokers the highest risk for the highest levels of earlier use. In Crohn's disease no clear dose-response pattern can be seen.

Shortly after Harries's report (3), case histories appeared. Two women with ulcerative colitis were described having relapses when stopping smoking and remissions when starting again $(15,16)$. This was also found in other studies $(17,18)$ although when asked the majority of patients with inflam. matory bowel disease (IBD) have not linked smoking habit to disease. It has been postulated that patients with ulcerative colitis could have a personality predisposing for nonsmoking or that early symptoms could explain onset after stopping smoking (19). The author found that nonsmokers with ulcerative colitis and Crohn's disease found it natural not to smoke and it was not bowel symptoms that had made ulcerative colitis patients stop smoking. In fact, all smokers with ulcerative colitis also denied that smoking made them worse, in contrast to Crohn's disease patients. Also, onset of ulcerative colitis after stopping smoking was in most cases not immediate but during the first four years after the stop, indicating a causal relation $(17,18)$, These facts, along with the epid. emiological findings, favour the hypothesis that smoking has a protective effect in ulcerative colitis.

Because pathogenesis in IBD is un. known, discussions on the effects of smoking must be hypothetical. Smoking has an immunosuppressive effect influencing both humoral and cellular immunity (20). If this was 'beneficial in ulcerative colitis it is difficult to understand why the effect would not be the same in Crohn's disease. Possible moderating effects of smoking on 


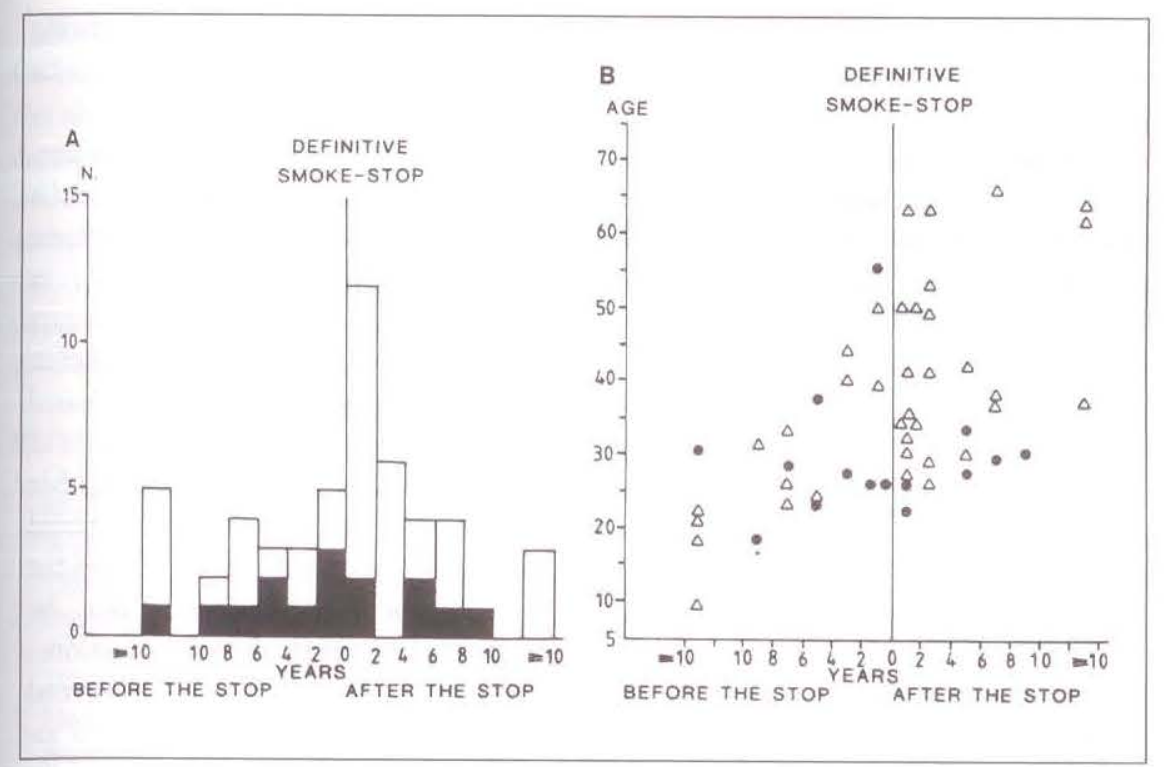

Figure 1) The relation between stopping smoking and disease onsets in ex-smokers with ulcerative colitis. Left Disease onsets during two-year periods before and after stopping smoking. Open columns Men; Closed columns Women. Right Age at disease onset in the same patients. Triangles Men; Circles Women. (Reproduced with permission from Benoni C, Nilsson A. Scand J Gastroenterol 1984;19:824-30)

leukocyte and macrophage function may be important in view of the massive mucosal invasion of these cells in ulcerative colitis (20).

The strongly chemotactic eicosanoid leukotriene $\mathrm{B}_{4}$ is formed in large amounts in the inflamed colonic mucosa in both ulcerative colitis and Crohn's disease. The possibility that smoking interferes with the lipoxygenase system with a decrease in the formation of leukotriene $\mathrm{B}_{4}$ in the colon must be considered. It has been suggested that smoking increases mucus secretion in patients with ulcerative colitis (21) and that it reduces gut permeability in healthy smokers (22).

Why smoking aggravates Crohn's disease is unknown. One possible mechanism could be through vascular influences, as Crohn's disease has been described recently as a multifocal vasculitis (23).

Undoubtedly, it is easy to give advice on stopping smoking to patients with Crohn's disease but so far no one has shown smoking to be a better alternative in the treatment of ulcerative colitis than sulphasalazine or the new 5-aminosalicylic acid compounds. Considering the vast negative effects of smoking on the whole system, eg, reduced natural killer cell activity, smoking cannot be introduced as an alternative in the treatment of a disease confined to the colon and linked to a risk of developing colorectal malignancy. Even with the knowledge of the possibility of relapses the few smokers with ulcerative colitis should be encouraged to stop smoking. Former smokers with ulcerative colitis having a severe relapse or a chronic, continuous course indicating colectomy could be tempted to try smoking and selective cases perhaps should have the option to do so. However, knowledge of the association between smoking and IBD should force us to advise young persons in families with IBD against starting smoking.

\section{DIET AND CROHN'S DISEASE}

In Crohn's disease, when giving dietary advice as part of long term treatment, one must consider: the extent and localization of the disease; former resections; the state of nutrition; and symptoms of activity. Malnutrition by disease activity or malabsorption must be corrected and the nutritional status maintained.

In Crohn's disease, morphometric changes and a significant reduction in disaccharidase activity in the spared jejunal mucosa have been demonstrated (24). In adults with Crohn's disease the prevalence of lactose malabsorption seems to be increased. However, only a minority seems to have clinical symptoms (25). Serum antibodies to cow's milk proteins are elevated in IBD, probably due to an increased dietary antigen uptake secondary to the disease (26). When interviewing patients with Crohn's disease on food intolerance, no difference in the tolerance of dairy products can be seen compared to a healthy control group (27). The mean intake of dairy products in IBD appears no different from that of the general population (28). Thus, in order not to deprive them of important nutrients, the patients should be advised to test dairy products.

Due to the increasing incidence of IBD in industrialized countries and the change in dietary habits during the past decades, a lot of interest has been focused on the pre-illness diet in Crohn's disease. Martini and Brandes (29) in 1976 were the first to describe an increased consumption of refined carbohydrates. This study was followed by several others confirming the association between high sugar consumption and Crohn's disease (30). Studies on dietary habits are afflicted with difficulties, including recall bias, relatively few comparable cases, the possibility of a long latent phase of illness before onset of bowel symptoms, choice of controls, different motivation in cases and controls and definition of intake. Does the habit precede the illness or is it a consequence of it? Most studies show a significantly higher intake of sugar in Crohn's disease patients compared with controls both at onset of symptoms and at interview, the amounts decreasing after diagnosis. The increased sugar intake during illness could well reflect the need for carbohydrates replacing fat because of fat intolerance in ileum disease or following resection.

The high intake of refined sugar has recently been found to be a separate risk factor not influenced by smoking (31). Interestingly, the smokers took only about one-third more sugar than 
the nonsmokers and the relative risk of having Crohn's disease in smokers was unrelated to added sugar intake.

The high caries risk in Crohn's disease patients could reflect both eating habits and amounts of sugar in food (32). Important in this aspect is also the high prevalence of smoking.

Dietary studies on fibre content and cereals have shown conflicting results, but in several studies a low intake of fruit and vegetables is associated with Crohn's disease (30). In a recent Swedish study, consumption of fast food has been associated with an increased risk of Crohn's disease, and high total intake of dietary fibre with a decreased risk (unpublished data).

If these dietary factors were of etiological importance, perhaps by altering the bacterial flora in the gut, one would expect diets avoiding possible risk foods to have an effect in keeping patients with Crohn's disease in remission. In a study from Bristol the clinical course of Crohn's disease patients treated with an unrefined carbohydrate, fibre-rich diet was compared retrospectively with the course of patients who had received no dietary instructions (33). Treatment with this diet was shown to have a favorable effect on course, but the results of this uncontrolled study have not been confirmed. Prospective studies have been conducted comparing the effect of different diets on maintenance of remission. A large British multicentre trial on mildly active or inactive Crohn's disease compared the clinical outcome in two groups of patients after two years (34). One group was advised to eat unrefined carbohydrates and increased dietary fibre and the other to eat refined carbohydrates and avoid unrefined. When entering the study the patients, if treated, were on sulphasalazine only. The clinical outcome in the two groups was the same. This was also the case in an Italian study, where patients with active Crohn's disease were allocated to eat either a low residue diet or a normal diet for a mean of 29 months (35). Worth noting is that $86 \%$ of the patients eating an unrestricted diet still avoided one or more permitted foods because of subjective intolerance. In $40 \%$ of the food intolerant patients, milk was the food specified.

In a small six month study, diet has been tested as sole maintenance therapy, showing the advantage of specific food exclusion over an unrefined carbohydrate, fibre-rich diet (36).

Individualized diet counselling has been evaluated in Crohn's disease and shown to improve the clinical course, probably by optimizing nutritional status (37).

\section{DIET AND ULCERATIVE COLITIS}

Since 1960, there has been speculation about an association between milk and ulcerative colitis. Taylor and Truelove (38) were the first to describe an increased incidence of high titre reactions to cow's milk proteins in ulcerative colitis. It was noted that patients with their first attack resembled normal subjects, and the marked high titre reactions occurred among patients with established chronic disease. A study on the consequence of a milk-free diet in ulcerative colitis showed that there was little fluctuation in the antibody titre in sera taken over a longer period from the same patient. The titre showed no relation to diet, clinical course or medical treatment, and provocation with milk did not produce a change in titres (39). These findings have been confirmed by later work (26). As in Crohn's disease, the antibody response is interpreted as a consequence of the disease rather than a cause.

The prevalence of lactose malabsorption in ulcerative colitis is the same as in the general population and thus depends on ethnic differences (40). The study by Pena and Truelove (41) in 1973 also confirmed earlier findings of villous abnormalities in ulcerative colitis. A temporary reduction of lactase activity during relapses was seen which was later confirmed by Gudmand-Höyer et al (42). The Oxford study found that the highest proportion of definite hypolactasiacs was among those with the most severe attacks, hence proposing hypolactasia to be an important secondary factor influencing the clinical course of ulcerative colitis (40).

However, even if lactase-deficient, patients do not necessarily notice it (42) and do not always have symptoms when fed with lactose (43). As in Crohn's disease, interviews on dietary intake do not reveal any differences in the intake of dairy products compared with the general population (28).

Thus, there are facts supporting that patients with ulcerative colitis should avoid milk products during relapses but a milk-free diet should not be prescribed routinely during remission.

As in Crohn's disease, several studies have been undertaken to associate ulcerative colitis with a pre-illness diet. The results should be interpreted with the same reservations mentioned above. In most of the studies there is no association between ulcerative colitis and refined sugar, cereals, milk products, fruits or vegetables (30). As in Crohn's disease, an association between ulcerative colitis and fast food can be seen (unpublished data). It has been proposed that even if no difference in fibre intake between ulcerative colitis patients and healthy controls is seen, the general diet may be poor in fibre and may favour development of ulcerative colitis in susceptible individuals (44). A prospective trial comparing relapse rates after either sulphasalazine or a high-fibre diet showed no differences and thus no sole benefit of fibres (45). In conclusion, no diet can replace medical treatment in long term therapy in IBD. Relapses do not depend on dietary factors, but in Crohn's disease individualized diet counselling is of great value in keeping the patients well nourished and thus in remission. In Crohn's disease, the patient may feel better when excluding certain foodstuffs, eg, milk or, if there are strictures, fibres. As there is an association be. tween Crohn's disease and refined carbohydrates, patients should be advised not to replace food not tolerated with sugar. In ulcerative colitis, the diet should be milk free during relapses, but if milk is tolerated, milk should be taken in between. 
Both in ulcerative colitis and Crohn's disease general restrictions in diet should be avoided in order not to deprive patients of important nutrients. Both ulcerative colitis and Crohn's disease patients will change diets according to how they feel, and the physician's task is to keep them in a good nutritional state.

\section{REFERENCES}

1. Gyde S, Prior P, Dew M, Saunders V, Waterhouse JAH, Allan RN. Mortality in ulcerative colitis. Gastroenterology 1982;83:36-43.

2. Samuelsson SM. Ulceros kolit och proctit. University of Uppsala. Thesis. 1976:128.

3. Harries AD, Baird A, Rhodes J. Nonsmoking: A feature of ulcerative colitis. Br Med J 1982;284;706.

4. Bures J, Fixa B, Komarkova O, Fingerland $\mathrm{A}$. Non-smoking: A feature of ulcerative colitis. Br Med J 1982;285:440. (Lett)

5. Jick H, Walker AM. Cigarette smoking and ulcerative colitis. N Engl J Med 1983;308:261-3.

6. Benoni C, Nilsson A. Smoking habits in patients with inflammatory bowel disease. Scand J Gastroenterol 1983;18:7. (Abst)

7. Benoni C, Nilsson A. Smoking habits in patients with inflammatory bowel disease. Scand J Gastroenterol 1984;19:824-30.

8. Penny WJ, Penny E, Mayberry JF, Rhodes J. Mormons, smoking and ulcerative colitis. Lancet 1983;ii:1315.

9. Holdstock G, Savage D, Harman M, Wright R. Should patients with inflammatory bowel disease smoke? Br Med J 1984;288:362

10. Logan RFA, Edmond M, Somerville KW, Langman MJS. Smoking and ulcerative colitis. Br Med J 1984;288:751.

11. Logan R, Langman MJS. Smoking and ulcerative colitis. Br Med J 1984:288:1307.

12. Somerville KW, Logan RFA, Edmond M, Langman MJS. Smoking and Crohn's disease. Br Med J

1984;289:954-6.

13. Gyde SN, Prior P, Alexander F, et al. Ulcerative colitis: Why is the mortality from cardiovascular disease reduced? Q J Med 1984;211:351-7.

14. Calkins BM. A meta-analysis of the role of smoking in inflammatory bowel disease. Dig Dis Sci 1989;34:1841-54.
15. de Castella H. Non-smoking: A feature of ulcerative colitis. Br Med J 1982;284:1706. (Lett)

16. Roberts CJ, Diggle R. Non-smoking: A feature of ulcerative colitis. $\mathrm{Br} \mathrm{Med}]$ 1982;285:440. (Lett)

17. Benoni C, Nilsson A. Smoking habits in patients with inflammatory bowel disease. A case-control study. Scand J Gastroenterol 1987;22:1130-6.

18. Motley RJ, Rhodes J, Ford GA, et al. Time relationships between cessation of smoking and onset of ulcerative colitis. Digestion 1987;37:125-7.

19. Bailar JC. Cigarettes, ulcerative colitis and interferences from uncontrolled data. N Engl J Med 1983;308:275.

20. Holt PG. Immune and inflammatory functions in cigarette smokers. Thorax 1987;42:241-9.

21. Cope GT, Heatley RV, Kelleher J. Smoking and colonic mucus in ulcerative colitis. Br Med J 1986;293:481.

22. Prytz H, Benoni C, Tagesson C. Does smoking tighten the gut? Scand ] Gastroenterol 1989;24:1084-8.

23. Wakefield AJ, Sawyerr AM, Dhillon AP, et al. Pathogenesis of Crohn's disease: Multifocal gastrointestinal infarction. Lancet 1989;ii:1057-62.

24. Dunne WT, Cooke WT, Allan RN. Enzymatic and morphometric evidence for Crohn's disease as a diffuse lesion of the gastrointestinal tract. Gut 1977;18:290-4

25. Pironi L, Callegari C, Cornia GL, Lami F, Migholi M, Barbara L. Lactose malabsorption in adult patients with Crohn's disease. Am J Gastroenterol 1988;83:1267-71.

26. Knoflach P, Park BH, Cunningham R, Weiser MM, Albini B. Serum antibodies to cow's milk proteins in ulcerative colitis and Crohn's disease. Gastroenterology 1987;92:479-85.

27. McDonald PJ, Fazio VW. What can Crohn's patients eat? Eur J Clin Nutr 1988;42:703-8.

28. Gee MI, Grace MGA, Wensel RH, Sherbaniuk RW, Thomson ABR. Nutritional status of gastroenterology outpatients: Comparison of inflammatory bowel disease with functional disorders. J Am Diet Assoc 1985;85:1591-9.

29. Martini GA, Brandes JW. Increased consumption of refined carbohydrates in patients with Crohn's disease. Klin Wochenschr 1976;54:367-71.

30. Persson PG, Ahlbom A, Hellers G. A review of dietary studies with emphasis on methodologic aspects. Crohn's dis- ease and ulcerative colitis. Scand J Gastroenterol 1987;22:385-9.

31. Katschinski B, Logan RFA, Edmond M, Langman MJS. Smoking and sugar intake are separate but interactive risk factors in Crohn's disease. Gut 1988;29:1202-6.

32. Sundh B, Emilson C-G. Salivary and microbial conditions and dental health in patients with Crohn's disease: A 3 . year study. Oral Surg Oral Med Oral Pathol 1989;67:286-90.

33. Heaton KW, Thornton JR, Emmett PM. Treatment of Crohn's disease with an unrefined carbohydrate fibre-rich diet. Br Med J 1979;2:764-6.

34. Ritchie JK, Wadsworth J, LennardJones JE, Rogers E. Controlled multicentre therapeutic trial of an unrefined carbohydrate, fibre rich diet in Crohn's disease. Br Med J 1987;295:517-20.

35. Levenstein S, Prantera C, Luzi C, D'Ubaldi A. Low residue or normal diet in Crohn's disease: A prospective controlled study in Italian patients. Gut 1985;26:989-93.

36. Alun Jones V, Workman E, Freeman $\mathrm{AH}$, Dickinson RJ, Wilson AJ, Hunter JO. Crohn's disease: Maintenance of remission by diet. Lancet 1985;i:177-80.

37. Innes S, Pinchbeck B, Thomson ABR. Diet counselling improves the clinical course of patients with Crohn's disease. Digestion 1988;39:7-19.

38. Taylor KB, Truelove SC. Circulating antibodies to milk proteins in ulcerative colitis. Br Med J 1961;2:924-9.

39. Wright R, Truelove SC. Circulating antibodies to dietary proteins in ulcerative colitis. Br Med J 1965;2:142-4.

40. Pena AS, Truelove SC. Hypolactasia and ulcerative colitis. Gastroenterology 1973;64:400-4.

41. Salem SN, Truelove SC. Small intestinal and gastric abnormalities in ul. cerative colitis. Br Med J 1965;1:827-31.

42. Gudmand-Höyer E, Binder V, Soltoft J. The small intestinal disaccharidase activity in ulcerative colitis. Scand ] Gastroenterol 1975;10:209-12.

43. Cady AB, Rhodes JB, Littman A, Crane RK. Significance of lactase deficit in ulcerative colitis. J Lab Clin Med 1967;70:279-86.

44. Thornton JR, Emmett PM, Heaton $\mathrm{KW}$. Diet and ulcerative colitis. $\mathrm{Br}$ Med J 1980;1:293-4.

45. Davies PS, Rhodes J. Maintenance of remission in ulcerative colitis with sulphasalazine or a high-fibre diet: A clinical trial. Br Med J 1978;1:1524-5. 


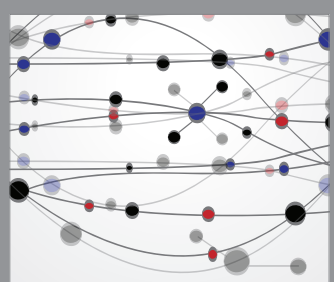

The Scientific World Journal
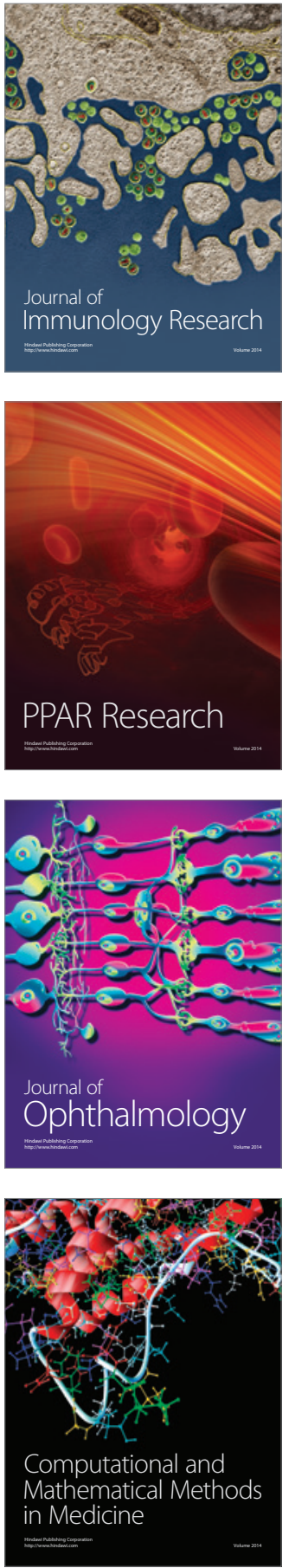

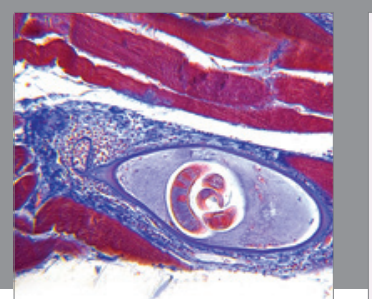

Gastroenterology Research and Practice

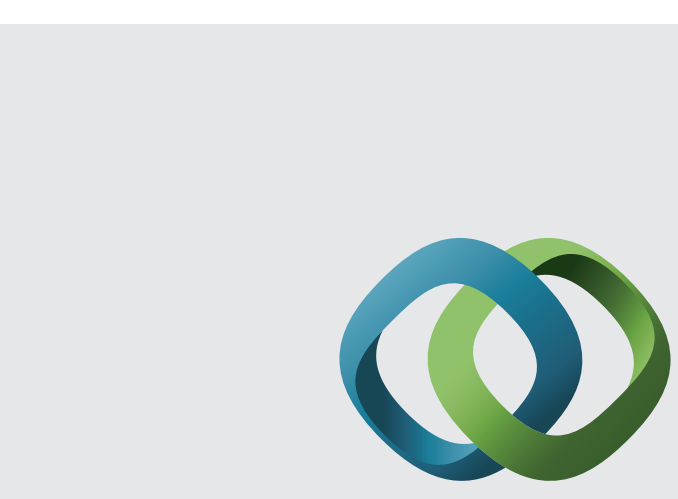

\section{Hindawi}

Submit your manuscripts at

http://www.hindawi.com
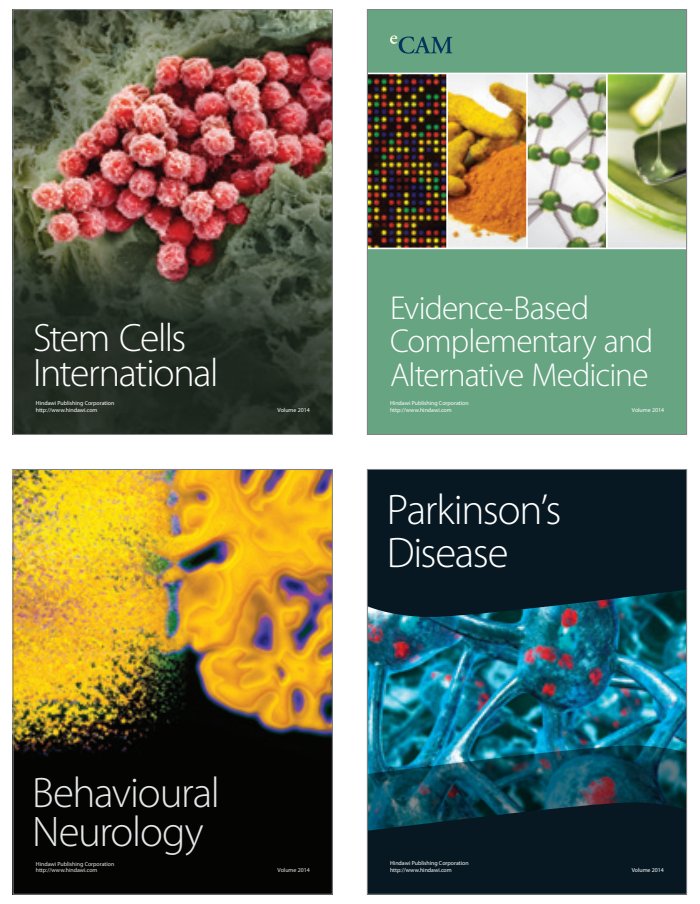
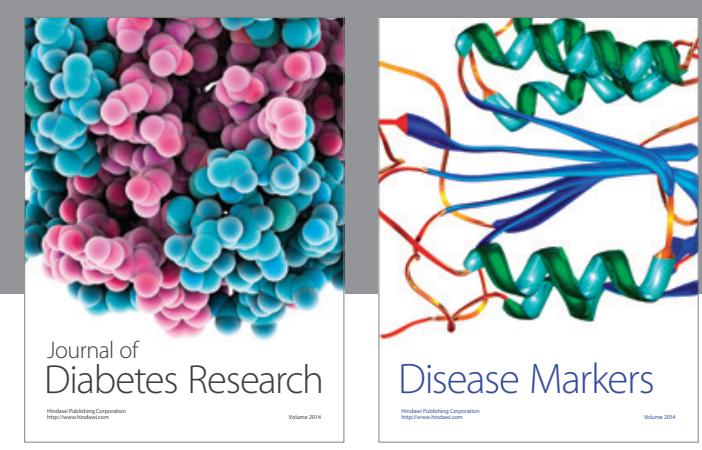

Disease Markers
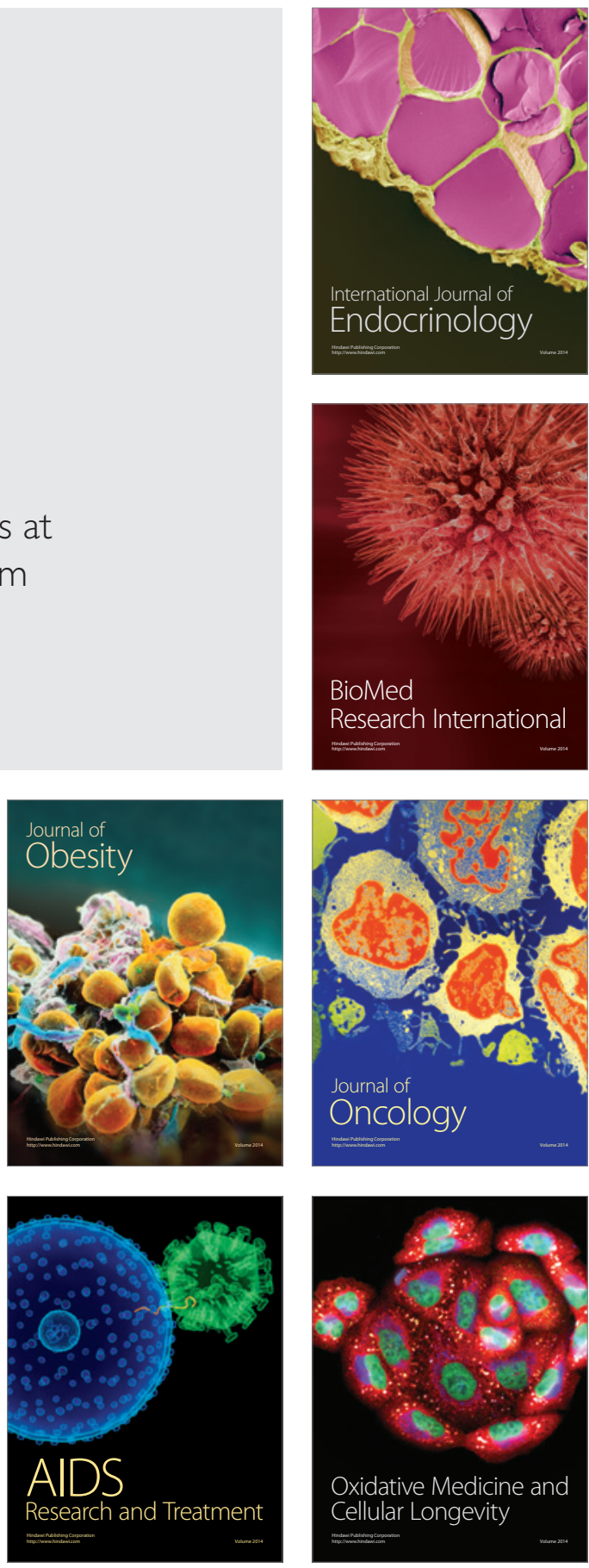